\title{
INFLUÊNCIA DE DIFERENTES NÍVEIS DE DESFOLHA NA PRODUÇÃO E QUALIDADE DOS FRUTOS DA BANANEIRA 'PRATA-ANÃ' 1
}

\author{
MARIA GERALDA VILELA RODRIGUES², MÁRIO SÉRGIO CARVALHO DIAS², \\ DILERMANDO DOURADO PACHECO
}

RESUMO - A desfolha da bananeira, de forma técnica, é uma prática agrícola que deve ser realizada periodicamente, objetivando eliminar aquelas cuja atividade fotossintética não atenda às exigências fisiológicas da planta, trazendo, entre outras vantagens, facilitar o controle de doenças. No caso das manchas das sigatokas, a eliminação de folhas atacadas é uma importante ferramenta auxiliar de seu controle, por reduzir a fonte de inóculo secundário, contudo deve ser feita com critério para não provocar danos mais graves que os causados pela própria doença. Sabe-se que as bananeiras do subgrupo Cavendish necessitam de, no mínimo, 11 e 8 folhas inteiras no momento da floração e da colheita, respectivamente, para produzir os fotoassimilados necessários para o adequado desenvolvimento do cacho, porém para bananeiras 'Prata-Anã' desconhece-se esse valor. Para evitar equívocos no manejo da 'Prata-Anã', avaliou-se por cinco ciclos produtivos consecutivos, o efeito de diferentes níveis de desfolha sobre a produção, definindo melhor relação nível de desfolha/ produção. Os tratamentos consistiram na manutenção de $4 ; 6 ; 8 ; 10 ; 12$ e 14 folhas por planta, além da testemunha (onde se retiraram apenas as folhas secas e quebradas). A massa dos cachos foi maior nas plantas mantidas com um mínimo de 12 folhas, assim como a maioria das características relacionadas à produção. Um adequado número de pencas e de frutos, assim como a maioria das características das pencas, ocorreu quando pelo menos 10 folhas permaneceram por planta. As desfolhas mais acentuadas, deixando-se apenas $4 ; 6 ; 8$ ou 10 folhas por planta, ao diminuir folhas velhas infestadas com doenças, principalmente sigatoka, permitiram maior preservação das folhas remanescentes nas plantas. Quando não se fez desfolha ou se deixou 12 ou 14 folhas por planta, verificou-se maior desfolha natural (redução no número de folhas sem que essas tenham sido retiradas), principalmente no quarto e quinto ciclos. Concluiu-se que desfolha mais acentuada reduziu o potencial produtivo de cachos pela perda de área fotossintética. Assim, a melhor

alternativa testada foi a manutenção de 10 a 12 folhas por planta, para se obterem adequado número de frutos e desenvolvimento dos mesmos, a fim de conciliar produção e fitossanidade do bananal.

Termos para indexação: Retirada de folhas, Musa sp., manejo do bananal, sigatoka.

\section{INFLUENCE OF DIFFERENT DEFOLIATION LEVELS ON THE PRODUCTION AND QUALITY OF 'PRATA-AN $\tilde{A}$ ' BANANA FRUITS}

\begin{abstract}
ABTRACT - Banana tree defoliation, in a rational way, it is a cultural practice that should be accomplished periodically, aiming at eliminating those leaves whose photosynthetic activity does not assist to the physiological needs of the plant, bringing among other advantages, facilitating the disease control. Concerning to sigatoka spots, the elimination of injured leaves is an important auxiliary tool for its control, for reducing the source of secondary inoculum, however it should be done with criterion to not cause more serious damages than those ones caused by the own disease. It is known that the banana trees of the subgroup Cavendish need 11 and 8 whole leaves in the moment of flowering and harvesting, respectively, to produce the necessary photoassimilates for the stuffing of the bunch, however for banana 'Prata-Anã' this is unknown yet. To avoid misunderstandings in the 'Prata-Anã' management, it was evaluated, for five consecutive productive cycles, the effect of different levels of defloliation on the production, defining a better relationship of defoliation level: production. The handlings consisted of the maintenance of 4, 6, 8, 10, 12 and 14 leaves per plant, besides the control (removal just of the dry and broken leaves). The mass of the bunches was greater in the plants maintained with a minimum of 12 leaves, as well as most of the characteristics related to production. An appropriate number of hands and fingers, as well as most of the hands characteristics, occurred when at least 10 leaves per plant were maintained. More accentuated defoliations, in which were kept 4, 6, 8 or 10 leaves per plant, reducing old diseased leaves, mainly with sigatoka, allowed greater preservation of the remaining leaves in the plants. When there was no defoliation, 12 or 14 leaves were kept per plant; it was verified larger natural defoliation, mainly in the fourth and fifth cycle, probably favored by the greatest pressure of the disease inoculum. It was concluded that more accentuated defoliations reduced the disease inoculum potential and better preserved the remaining leaves in the plants, however, it reduced the productive potential of bunches by the loss of photosynthetic area. Thus, the best tested alternative was the maintenance of 10 to 12 leaves per plant to obtain appropriate number of fruits and their stuffing, in order to conciliate production and fitossanity of the banana plantation.
\end{abstract}

Index Terms: leaves removal, Musa sp, banana plantation management, sigatoka.

\footnotetext{
${ }^{1}$ (Trabalho 195-08). Recebido em: 25-07-2008. Aceito para publicação em: 03-04-2009. Trabalho financiado pelo Banco do Nordeste e Consórcio de Pesquisa do Jaíba

${ }^{2}$ Pesquisadores da EPAMIG/URNM, D.Sc., Bolsistas da FAPEMIG, CEP 39527-000, Nova Porteirinha - MG, CP. 12. magevr@epamig.br; mariodias@epamig.br

${ }^{3}$ Professor IFET, D.Sc., Fazenda São Geraldo, Bom Jardim, CEP 39480-000, Januária - MG. ddpacheco.agro@gmail.com
} 


\section{INTRODUÇ̃̃O}

Segundo Soto (2000), a desfolha da bananeira é uma prática agrícola que deve ser realizada periodicamente, objetivando eliminar folhas cuja atividade fotossintética não atenda às exigências fisiológicas da planta. Esta técnica melhora o arejamento e a iluminação interna do bananal, acelera o desenvolvimento dos filhos, facilita o desbaste e o controle de pragas e doenças que parasitam, o que as torna fontes potenciais de inóculo.

O norte de Minas conta hoje com aproximadamente 8.000 ha cultivados com banana, basicamente 'Prata-Anã', distribuídos, em sua maioria, em pequenas e médias propriedades, onde se observa a descontinuidade de controle fitossanitário, o que favorece o aumento do inóculo de doenças, principalmente da sigatoka-amarela.

A sigatoka-amarela é uma doença fúngica típica das folhas da bananeira, com efeito indireto na produção, resultante das toxinas que são lançadas na seiva da planta e na redução da área foliar funcional, causando a morte prematura de grandes áreas da superfície da folha, senão de toda ela, o que resulta em importante redução da área fotossintética (González, 1987). Além dos prejuízos causados pela coalescência de lesões, que potencializa a redução da área foliar, promove alterações do metabolismo da planta, com consequente maturação desuniforme e precoce dos frutos, perfilhamento lento, perda de vigor da família com enfraquecimento do rizoma, redução do número de pencas e tamanho dos frutos (Alves et al., 1997; Pereira, 1999).

Estratégias de controle integrado da sigatoka-amarela devem ser adaptadas para os diferentes sistemas de produção. Entre essas, Mourichon (2002) cita que algumas práticas culturais afetam a pressão de inóculo no campo, como a remoção de folhas, métodos de irrigação e densidade de plantio. Entre as práticas culturais mencionadas, uma das importantes ferramentas auxiliares é a eliminação de folhas atacadas ou parte delas, para reduzir a fonte de inóculo secundário (Pereira et al., 1999). A eliminação de forma técnica, de folhas atacadas ou parte destas folhas, é de grande importância, contudo deve ser feita com bastante critério para não provocar danos maiores que a própria doença (Alves et al., 1997).

Segundo González (1987), se as folhas da bananeira são severamente atacadas pela sigatokaamarela, a planta pode apresentar apenas quatro a cinco folhas sadias no momento da colheita. $\mathrm{O}$ autor relata também que os cachos apresentam qualidade para exportação quando são colhidos de plantas que apresentam, no mínimo, sete a oito folhas sadias. Carvajal (1991) cita que em regiões com condições desfavoráveis ao ataque de doenças foliares, a planta pode apresentar até 16 folhas verdes, com duração média de 160 dias. Afirma, ainda, que uma planta necessita de oito folhas durante todo o seu ciclo, suportando perdas de até $50 \%$ de sua folhagem em qualquer época do seu ciclo vegetativo, sem que isso afete seus componentes de desenvolvimento e qualidade da produção. Robinson (1996) recomenda que as folhas de bananeira sejam eliminadas quando apresentam mais que $50 \%$ de sua área tomada por lesões causadas por doença, ou quando estão em senescência e apresentando colapso de pecíolo, sendo importante para um bom rendimento do cacho de 'Williams' que a planta tenha um mínimo de 12 folhas na floração e nove na colheita.

Trabalhos realizados por Lassoudière na Costa de Marfim (Soto, 2000), com a retirada de folhas de bananeiras do subgrupo Cavendish, confirmaram as afirmações dos autores anteriores, e a manutenção de oito folhas foi suficiente para um desenvolvimento normal do cacho até a colheita. Em outro trabalho, conduzido em Burgershall (África do Sul) com 'Williams', a redução da massa do cacho foi considerável em plantas com uma ou duas folhas; esta redução foi de 10 a $15 \%$ em plantas com três a cinco folhas; quando as plantas foram mantidas com seis ou mais folhas, houve pouca variação na massa do cacho, que se manteve entre 45 e $50 \mathrm{~kg}$, concluindose que oito ou nove folhas são suficientes para o crescimento normal dos frutos (Robinson e Anderson, 1993). Os mesmos autores acreditam que plantas maiores tenham reservas que podem ser utilizadas para o crescimento normal dos frutos. Em trabalho desenvolvido com o plátano 'Dominico-Hárton', em Guayquil, observou-se que sob diferentes níveis de desfolha feita no momento da floração, as plantas mantidas com seis folhas tiveram comportamento semelhante às plantas que foram mantidas com nove folhas, porém as plantas mantidas com apenas três folhas tiveram a produção de matéria seca dos frutos severamente afetada (Cayon, 1999).

Para bananas do subgrupo Cavendish e plátanos, há, portanto, resultados que indicam os valores oito a nove como sendo o mínimo de folhas no momento da floração, necessário para o bom desenvolvimento do cacho. Porém, para bananeiras 'Prata-Anã' desconhece-se esse valor. Esta é uma cultivar pertencente a um grupo genômico diferente (AAB) dos materiais geralmente estudados, apresenta porte, área foliar e peso médio de cacho também diferentes. Estas diferenças sugerem que o manejo da desfolha da 'Prata-Anã' cultivada sob irrigação no norte de Minas, deva ser mais bem estudado. O objetivo deste trabalho foi identificar o nível máximo de desfolha da 'Prata-anã', que não interfira negativamente na produção, tornando possível uma recomendação segura, evitando equívocos no manejo do bananal, com prejuízos para o produtor, causados por desfolha insuficiente ou excessiva. 


\section{MATERIAL E MÉTODOS}

O trabalho foi conduzido na Fazenda Experimental de Mocambinho (FEMO), pertencente à Epamig, localizada no Perímetro de Irrigação do Jaíba. A pluviosidade média da região é de aproximadamente $871 \mathrm{~mm}$, temperatura média anual de $24{ }^{\circ} \mathrm{C}$, insolação de 2.763 horas anuais, umidade relativa média de $70.6 \%$, e clima Aw segundo a classificação de Köeppen (Jacomine et al., 1979). O solo da área foi classificado como NeossoloFlúvico, contendo 104; 789 e $107 \mathrm{~g} \mathrm{~kg}^{-1}$ de argila, areia e silte, respectivamente (franco-arenoso). $\mathrm{O}$ bananal utilizado foi implantado em fevereiro de 1998, no espaçamento 3,0 × 2,7 m, utilizando mudas micropropagadas, cultivado sob microaspersão.

Durante todo o período de condução do experimento, foram mantidas as operações de manejo do bananal, conforme recomendações para a região, resumidas no Informe Agropecuário no ${ }^{\circ} 196$ (Informe Agropecuário, 1999), como irrigação, adubação mensal (de acordo com resultados de análise de solo e folhas coletadas a cada três meses), desbrota, retirada da inflorescência masculina, controle de broca, monitoramento e controle de nematoides e da sigatoka-amarela. O controle de sigatokaamarela foi baseado no monitoramento realizado na bordadura do bananal, por meio de pulverizações com equipamento costal (conforme feito por grande parte dos produtores da região, uma vez que, em algumas áreas, é proibida a pulverização aérea) que nem sempre resulta na redução adequada dos sintomas e do inóculo, exigindo ainda mais o apoio de técnicas complementares, como a desfolha (não há controle químico que dispense o controle cultural).

O ensaio constituiu-se de sete níveis de desfolha da bananeira 'Prata-Anã', em cinco repetições distribuídas na área, em blocos casualizados, avaliados por cinco ciclos consecutivos. Cada parcela foi composta por 12 plantas, sendo que apenas as duas centrais foram avaliadas. $\mathrm{O}$ número de folhas mantidas por planta, referente aos tratamentos, foram: $4 ; 6 ; 8 ; 10 ; 12 ; 14$ e $\mathrm{T}$, onde a testemunha $(\mathrm{T})$ equivaleu à retirada apenas das folhas secas ou com pecíolo quebrado.

O trabalho iniciou-se em janeiro de 2002, extraindo uma folha por planta-filha com porte de $2 \mathrm{~m}$ de altura, repetindo-se esse procedimento a cada quinze dias até que se atingisse o número de folhas equivalente ao tratamento. Este acompanhamento quinzenal foi feito até a floração. Na colheita dos cachos, foram feitas as seguintes avaliações: data, número de folhas vivas, massa do cacho, número de frutos e massa da segunda e penúltima penca, caracterização do fruto central da mão externa da segunda e penúltima penca (comprimento, diâmetro e peso). Os dados foram submetidos à análise de variância e ao teste de média de Tukey (5\%), a fim de identificar variação significativa entre tratamentos.

\section{RESULTADOS E DISCUSSÃO}

O período para colheita de todos os cachos foi menor nos tratamentos mantidos com 4 folhas $(4,5$ meses) e na testemunha (5,4 meses). No primeiro caso por insuficiência de folhas e exposição ao sol (alguns cachos apresentaram sintomas de queima), e no segundo, possivelmente, antecipada pela alta infestação de sigatoka-amarela (apesar de essa não ter sido quantificada). Os tratamentos mantidos com $6 ; 8 ; 10 ; 12$ e 14 folhas foram colhidos com 8,2; 7,6; 6,3 e 8,9 meses, respectivamente.

O número de folhas vivas (com pelo menos $50 \%$ de área verde) da planta na data da colheita do cacho não foi dependente apenas da desfolha equivalente aos tratamentos, havendo interação entre os tratamentos (número de folhas mantidas na planta) e o ciclo avaliado (Figura 1). Nos tratamentos com redução mais drástica de folhas (manutenção de 4; $6 ; 8$ e 10 folhas por planta), onde as folhas mais velhas e, portanto, mais infestadas por sigatoka foram eliminadas, houve maior preservação daquelas que foram mantidas, ficando o número final de folhas mais próximo ao número de folhas mantido por tratamento. Nas plantas onde houve menor redução do número de folhas pelo tratamento $(12 ; 14$ e testemunha), o número final foi reduzido naturalmente (sem interferência) em 1 a 6 folhas, principalmente no quarto e no quinto ciclos, indicando efeito cumulativo. Por exemplo: no tratamento T4, o número médio de folhas na data da colheita variou de 3,9 a 4,0 , ou seja, o mesmo mantido pelo tratamento; já no tratamento T14, o número médio de folhas na data da colheita variou de 9,3 a 12,2, ou seja, inferior ao mantido pelo tratamento.

Observou-se efeito do ciclo de cultivo no número de folhas vivas apenas quando foram mantidas mais de 12 folhas por planta (Figura 1). Provavelmente, isso se deu porque a manutenção de folhas mais velhas teve efeito cumulativo sobre a concentração de inóculo de sigatoka, confirmando a importância da desfolha no controle dessa doença. Como as folhas representam o aparato fotossintético da planta, houve interferência dessas em vários outros parâmetros avaliados.

Não existiu interação significativa entre ciclo e número de folhas, para a altura da planta, dias entre a floração e a colheita, e intervalo de colheita entre ciclos (Tabela 1). As plantas foram mais altas nos dois primeiros ciclos, principalmente quando mantidas com mais de 10 folhas. A colheita foi cerca de 12 dias mais precoce no terceiro e quarto ciclos e nas plantas com até 10 folhas. A duração do segundo ciclo de produção foi menor, aumentando cerca de um mês a partir do tratamento equivalente à manutenção de oito folhas na planta.

A produção da planta não foi influenciada pela interação entre ciclo e número de folhas. 
Os primeiros ciclos, especialmente o primeiro, produziram cachos mais pesados e com maior número de frutos e pencas, apesar de certa instabilidade no número de pencas (Tabela 1). Os cachos foram mais pesados em plantas mantidas com um mínimo de 12 folhas, sendo maiores os números de pencas e de frutos nas plantas a partir de 10 folhas. Como a massa do cacho é resultado, entre outros, da capacidade fotossintética da planta e, portanto, do número de folhas vivas (área foliar fotossinteticamente ativa), a manutenção de maior quantidade possível desse tipo de folha mostrou-se mais favorável.

Houve efeito de interação entre ciclo e número de folhas nas características de comprimento e diâmetro do fruto central da segunda penca, e de massa do fruto central da penúltima penca. $\mathrm{O}$ fruto central da segunda penca foi mais curto quando as plantas foram mantidas com menos de 10 folhas, havendo diferença entre ciclos apenas quando $4 ; 10$ e 12 folhas foram mantidas (Figura 2). O diâmetro do mesmo fruto foi maior nas plantas mantidas com mais de oito folhas, havendo efeito de ciclo quando se mantiveram 4; 10 e 12 folhas (Figura 3). O comprimento do fruto foi, portanto, mais exigente no aporte foliar que o diâmetro.
A massa do fruto central da penúltima penca foi superior quando as plantas foram mantidas com mais de oito folhas no primeiro e quarto ciclos, acima de seis no segundo ciclo, acima de 12 no quarto, e sem efeito de tratamento no quinto ciclo (Figura 4). Houve efeito do ciclo na massa do fruto central da penúltima penca apenas quando as plantas foram mantidas com mais de 12 folhas.

Os fatores ciclo e número de folhas interferiram significativamente em todas as características avaliadas da segunda e penúltima pencas, apesar de não haver interação entre eles (Tabela 2). Houve redução na massa da segunda penca em resposta à intensificação da desfolha, atribuindo-se esse efeito ao menor número de frutos produzidos, já que a massa do fruto central não foi alterada. Da mesma forma, houve redução na massa da penúltima penca, no tempo, com valores mínimos para diâmetro e comprimento do fruto central no segundo e quinto ciclos.

A maioria das características avaliadas nas pencas apresentou valores superiores quando as plantas foram mantidas com, pelo menos, 10 folhas. As características relacionadas à massa exigiram um mínimo de 12 folhas, provavelmente por serem imediatamente dependentes de fotoassimilados.

TABELA 1 - Características das plantas e da produção, dadas por altura das plantas, dias entre a floração e a colheita (DFC), ciclo de produção(ICC), massa do cacho (MC), número de pencas (NP), número de frutos do cacho (NFC), nos cinco primeiros ciclos de produção da bananeira 'Prata-Anã', em cada tratamento (plantas mantidas com $4 ; 6 ; 8 ; 10 ; 12$ e 14 folhas, e a testemunha).

\begin{tabular}{|c|c|c|c|c|c|c|}
\hline & ALTURA & $\begin{array}{l}\text { DFC } \\
\text { (Dias) }\end{array}$ & $\begin{array}{c}\text { ICC } \\
\text { (Dias) }\end{array}$ & $\begin{array}{l}\text { MC } \\
(\mathrm{kg})\end{array}$ & NP & $\mathrm{NFC}$ \\
\hline \multicolumn{7}{|c|}{ TRATAMENTO } \\
\hline 4 & $3,48 \mathrm{C}$ & $161,10 \mathrm{~A}$ & $196 \mathrm{C}$ & $15,54 \mathrm{D}$ & $10,94 \mathrm{D}$ & $136,42 \mathrm{D}$ \\
\hline 6 & $3,71 \mathrm{~B}$ & $158,56 \mathrm{AB}$ & 204BC & $20,76 \mathrm{C}$ & $11,66 \mathrm{BC}$ & $154,26 \mathrm{BC}$ \\
\hline 8 & $3,80 \mathrm{~B}$ & $159,50 \mathrm{~A}$ & $240 \mathrm{~A}$ & $22,58 \mathrm{C}$ & $11,56 \mathrm{C}$ & $150,84 \mathrm{C}$ \\
\hline 10 & $3,89 \mathrm{AB}$ & $156,14 \mathrm{AB}$ & $227 \mathrm{AB}$ & $25,67 \mathrm{~B}$ & $12,20 \mathrm{AB}$ & $167,42 \mathrm{~A}$ \\
\hline 12 & $4,02 \mathrm{~A}$ & $141,30 \mathrm{C}$ & $236 \mathrm{~A}$ & $28,17 \mathrm{~A}$ & $12,18 \mathrm{AB}$ & $167,66 \mathrm{~A}$ \\
\hline 14 & $4,05 \mathrm{~A}$ & $152,74 \mathrm{ABC}$ & $235 \mathrm{~A}$ & $29,44 \mathrm{~A}$ & $12,16 \mathrm{AB}$ & $166,16 \mathrm{AB}$ \\
\hline $\mathrm{T}$ & $4,02 \mathrm{~A}$ & $141,30 \mathrm{BC}$ & $235 \mathrm{~A}$ & $30,16 \mathrm{~A}$ & $12,68 \mathrm{~A}$ & $174,32 \mathrm{~A}$ \\
\hline Teste F & $24,064^{* *}$ & $5,559^{* * *}$ & $7,45^{* *}$ & $82,201^{* *}$ & $17,704^{* *}$ & $19,293^{* *}$ \\
\hline $\operatorname{DMS}(5 \%)$ & 0,178 & 13,342 & 26,930 & 0,586 & 0,567 & 12,514 \\
\hline \multicolumn{7}{|l|}{ CICLOS } \\
\hline 1 & $4,09 \mathrm{~A}$ & $147,67 \mathrm{~B}$ & & $27,20 \mathrm{~A}$ & $12,24 \mathrm{~A}$ & $179,96 \mathrm{~A}$ \\
\hline 2 & $3,90 \mathrm{~B}$ & $148,10 \mathrm{~B}$ & 211B & $25,30 \mathrm{AB}$ & $12,03 \mathrm{AB}$ & $160,98 \mathrm{~B}$ \\
\hline 3 & $3,76 \mathrm{C}$ & $162,64 \mathrm{~A}$ & $230 \mathrm{~A}$ & $23,91 \mathrm{~B}$ & $11,47 \mathrm{C}$ & $150,24 \mathrm{CD}$ \\
\hline 4 & $3,75 \mathrm{C}$ & $161,83 \mathrm{~A}$ & $226 \mathrm{AB}$ & $24,97 \mathrm{~B}$ & $12,06 \mathrm{ABC}$ & $159,10 \mathrm{DE}$ \\
\hline 5 & $3,76 \mathrm{C}$ & $147,63 \mathrm{~B}$ & $232 \mathrm{~A}$ & $21,71 \mathrm{C}$ & $11,76 \mathrm{BC}$ & $147,63 \mathrm{E}$ \\
\hline Teste F & $16,602^{* *}$ & $8,682^{* *}$ & $3,79^{* *}$ & $16,516^{* *}$ & $6,947^{* *}$ & $25,508^{* *}$ \\
\hline $\operatorname{DMS}(5 \%)$ & 0,139 & 10,426 & 17,714 & 0,05 & 0,443 & 9,778 \\
\hline \multicolumn{7}{|c|}{ TRATAMENTOS X CICLOS } \\
\hline Teste F & $0,931^{\mathrm{NS}}$ & $1,092^{\mathrm{NS}}$ & $1,30^{\mathrm{NS}}$ & $1,097^{\mathrm{NS}}$ & $1,045^{\mathrm{NS}}$ & $1,057^{\mathrm{NS}}$ \\
\hline $\mathrm{CV}$ & 7,80 & 14,63 & 18,02 & 16,82 & 8,02 & 13,21 \\
\hline
\end{tabular}

Mesmas letras maiúsculas na coluna, por seção (número de folhas ou ciclos), não diferem entre si, pelo teste Tukey (5\%).

** Diferença significativa a $1 \%$ ou $5 \%$ de probabilidade, ns-não-significativa. 
TABELA 2 - Características da segunda e penúltima pencas do cacho, dada por número de frutos (NF), massa da penca (M), massa do fruto central (MFC), diâmetro do fruto central (DFC), comprimento do fruto central (CFC), em cinco ciclos de produção da bananeira 'Prata-Anã', em cada tratamento (desfolha com redução do número de folhas a: $4 ; 6 ; 8 ; 10 ; 12 ; 14$ e testemunha).

\begin{tabular}{|c|c|c|c|c|c|c|c|}
\hline & \multicolumn{3}{|c|}{ Segunda penca } & \multicolumn{4}{|c|}{ Penúltima penca } \\
\hline & NF & $\begin{array}{c}\mathrm{M} \\
(\mathrm{kg})\end{array}$ & $\begin{array}{c}\mathrm{MFC} \\
(\mathrm{g})\end{array}$ & NF & $\begin{array}{c}\mathrm{M} \\
(\mathrm{kg})\end{array}$ & $\begin{array}{l}\mathrm{DFC} \\
(\mathrm{cm})\end{array}$ & $\begin{array}{l}\text { CFC } \\
(\mathrm{cm})\end{array}$ \\
\hline \multicolumn{8}{|c|}{ TRATAMENTO } \\
\hline 4 & $17,24 \mathrm{~B}$ & $1,28 \mathrm{D}$ & $75,64 \mathrm{E}$ & $15,24 \mathrm{D}$ & $1,24 \mathrm{E}$ & $3,47 \mathrm{C}$ & $14,24 \mathrm{C}$ \\
\hline 6 & $17,90 \mathrm{AB}$ & $1,64 \mathrm{C}$ & $95,86 \mathrm{DE}$ & $15,28 \mathrm{CD}$ & $1,46 \mathrm{D}$ & $3,65 \mathrm{~B}$ & $14,84 \mathrm{BC}$ \\
\hline 8 & $17,68 \mathrm{AB}$ & 1,95 B & $113,64 \mathrm{CD}$ & $15,46 \mathrm{BCD}$ & $1,61 \mathrm{C}$ & $3,74 \mathrm{AB}$ & $15,34 \mathrm{~B}$ \\
\hline 10 & $18,30 \mathrm{~A}$ & $2,19 \mathrm{~B}$ & $121,40 \mathrm{BC}$ & $16,04 \mathrm{AB}$ & $1,69 \mathrm{BC}$ & $3,78 \mathrm{AB}$ & $15,58 \mathrm{AB}$ \\
\hline 12 & $18,24 \mathrm{~A}$ & $2,55 \mathrm{~A}$ & $138,14 \mathrm{AB}$ & $15,92 \mathrm{AB}$ & $1,81 \mathrm{AB}$ & $3,79 \mathrm{AB}$ & $16,16 \mathrm{~A}$ \\
\hline 14 & $18,06 \mathrm{AB}$ & $2,55 \mathrm{~A}$ & $156,50 \mathrm{~A}$ & $15,88 \mathrm{ABC}$ & $1,87 \mathrm{~A}$ & $3,86 \mathrm{~A}$ & $16,24 \mathrm{~A}$ \\
\hline $\mathrm{T}$ & $18,38 \mathrm{~A}$ & $2,62 \mathrm{~A}$ & $143,34 \mathrm{AB}$ & $16,24 \mathrm{~A}$ & $1,89 \mathrm{~A}$ & $3,79 \mathrm{AB}$ & 16,26 \\
\hline Teste F & $4,078^{* *-}$ & $55,314^{* *}$ & $23,499^{* *}$ & $7,075^{* *}$ & $42,496^{* *}$ & $9,572^{* *}$ & $16,84^{* *}$ \\
\hline $\operatorname{DMS}(5 \%)$ & 0,840 & 0,288 & 24,486 & 0,05 & 0,153 & 0,174 & 0,794 \\
\hline \multicolumn{8}{|l|}{ CICLOS } \\
\hline 1 & $18,45 \mathrm{~A}$ & $2,21 \mathrm{~A}$ & $116,93 \mathrm{~A}$ & $15,9 \mathrm{~A}$ & $1,76 \mathrm{~A}$ & $3,74 \mathrm{AB}$ & $15,81 \mathrm{~A}$ \\
\hline 2 & $18,24 \mathrm{~A}$ & $2,15 \mathrm{AB}$ & $120,38 \mathrm{~A}$ & $15,96 \mathrm{~A}$ & $1,61 \mathrm{BC}$ & $3,66 \mathrm{~B}$ & $15,43 \mathrm{AB}$ \\
\hline 3 & $17,50 \mathrm{~B}$ & $2,11 \mathrm{AB}$ & $116,67 \mathrm{~A}$ & $15,11 \mathrm{~B}$ & $1,71 \mathrm{AB}$ & $3,85 \mathrm{~A}$ & $15,96 \mathrm{~A}$ \\
\hline 4 & $18,06 \mathrm{AB}$ & $2,15 \mathrm{AB}$ & $130,84 \mathrm{~A}$ & $15,94 \mathrm{~A}$ & $1,67 \mathrm{AB}$ & $3,75 \mathrm{AB}$ & $15,48 \mathrm{AB}$ \\
\hline 5 & $17,57 \mathrm{~B}$ & 1,93 B & $118,40 \mathrm{~A}$ & $15,70 \mathrm{~A}$ & $1,52 \mathrm{C}$ & $3,63 \mathrm{~B}$ & $14,93 \mathrm{~B}$ \\
\hline Teste F & $6,360^{* *}$ & $3,348^{* *}$ & $1,427^{\mathrm{NS}}$ & $8,077^{* *}$ & $8,606^{* *}$ & $6,180^{* *}$ & $6,24^{* *}$ \\
\hline $\operatorname{DMS}(5 \%)$ & 0,656 & 0,225 & 19,134 & 0,485 & 0,120 & 0,136 & 0,620 \\
\hline \multicolumn{8}{|c|}{ TRATAMENTO X CICLOS } \\
\hline Teste F & $1,252^{\mathrm{NS}}$ & $1,238^{\mathrm{NS}}$ & $1,234^{\mathrm{NS}}$ & $1,207^{\mathrm{NS}}$ & $1,126^{\mathrm{NS}}$ & $1,383^{\mathrm{NS}}$ & $1,26^{\mathrm{NS}}$ \\
\hline $\mathrm{CV}$ & 7,87 & 23,03 & 34,18 & 6,66 & 15,61 & 7,88 & 8,61 \\
\hline
\end{tabular}

Mesmas letras maiúsculas na coluna, por seção (número de folhas ou ciclos), não diferem entre sí, pelo teste Tukey (5\%).

** Diferença significativa a $1 \%$ ou $5 \%$ de probabilidade, ns-não-significativa.

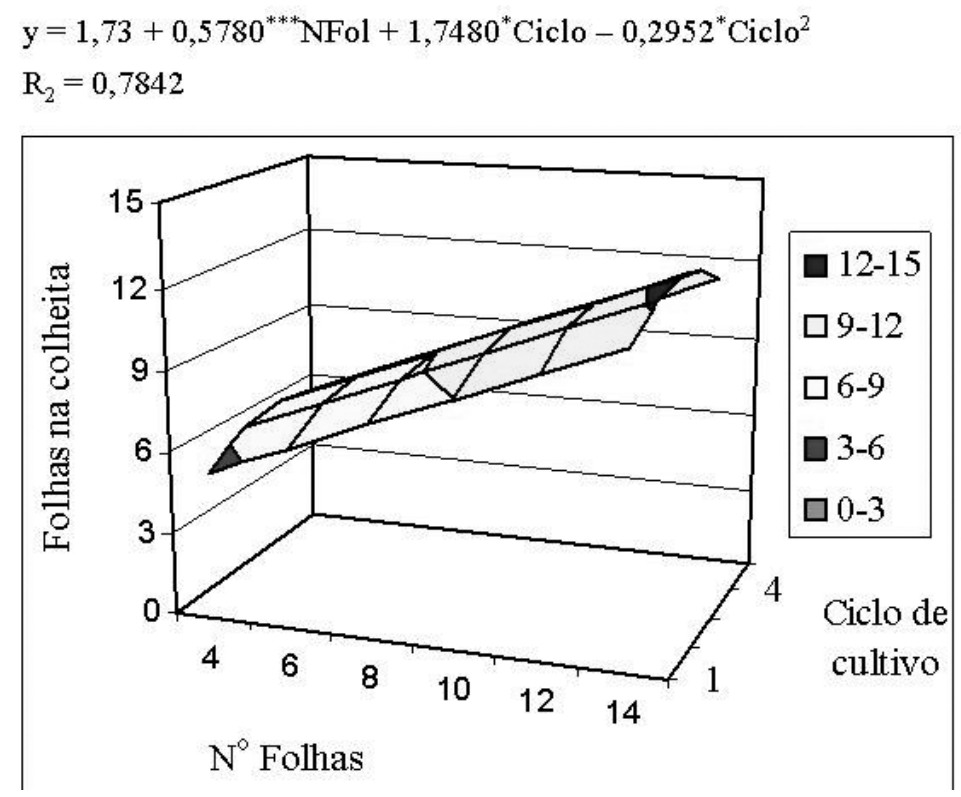

FIGURA 1 - Quantidade de folhas à época da colheita em função do número de folhas iniciais e do ciclo de cultivo. 


$$
\begin{aligned}
& \mathrm{y}=14,07+0,4151^{* * *} \mathrm{NFol} \\
& \mathrm{R}_{2}=0,9499
\end{aligned}
$$

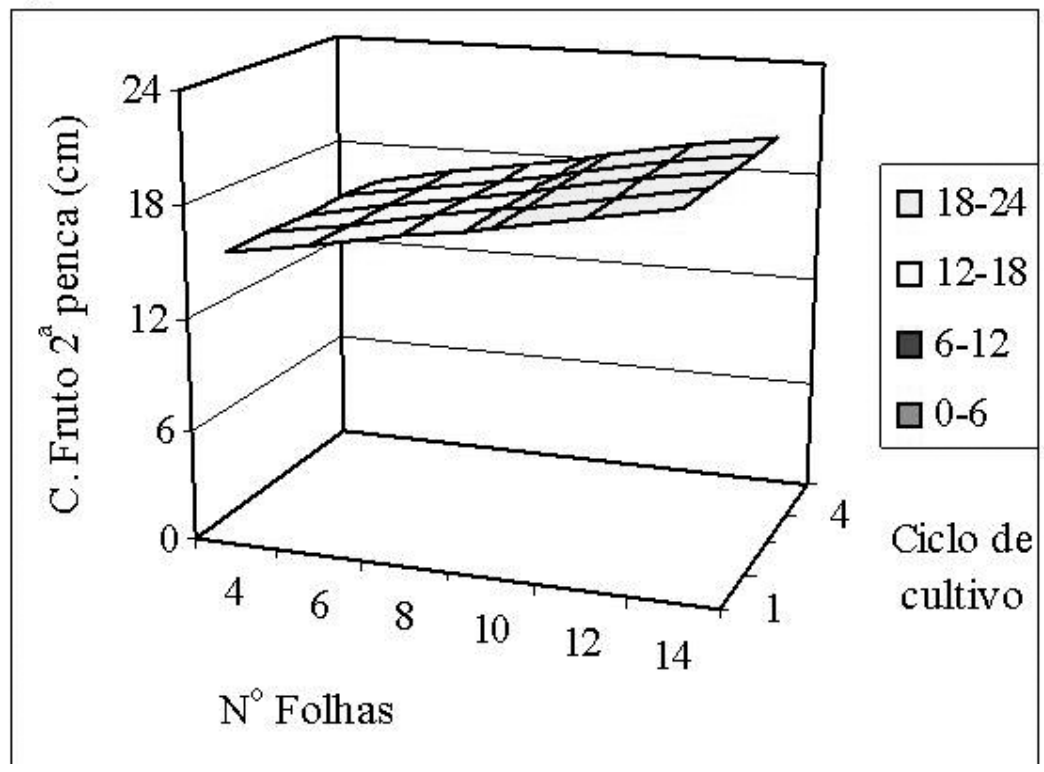

FIGURA 2 - Comprimento do fruto central da $2^{\mathrm{a}}$ penca de banana em função do número de folhas iniciais e do ciclo de cultivo.

$$
\begin{aligned}
& \mathrm{y}=2,63+0,0729^{* * *} \mathrm{NFol}+0,2635^{*} \mathrm{Ciclo}-0,0435^{*} \mathrm{Ciclo}^{2} \\
& \mathrm{R}_{2}=0,7161
\end{aligned}
$$

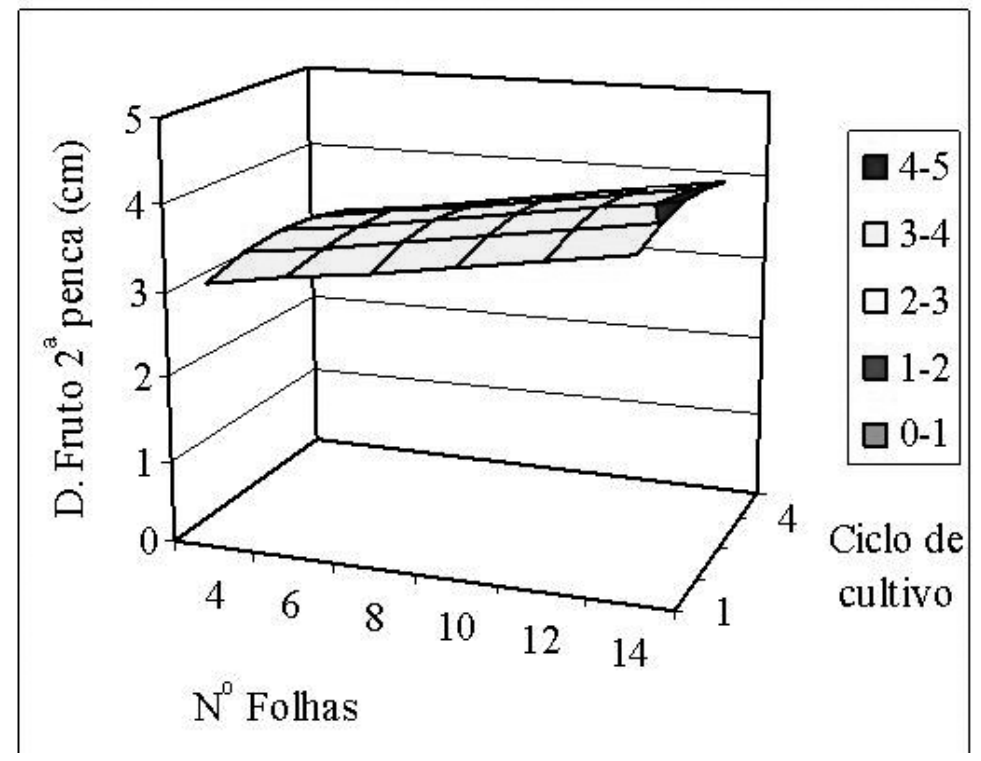

FIGURA 3 - Diâmetro do fruto central da $2^{\mathrm{a}}$ penca de banana em função do número de folhas iniciais e do ciclo de cultivo. 


$$
\begin{aligned}
& \mathrm{y}=82,47+3,1411^{* * *} \mathrm{NFol}-2,3800^{*} \text { Ciclo } \\
& \mathrm{R}_{2}=0,6988
\end{aligned}
$$

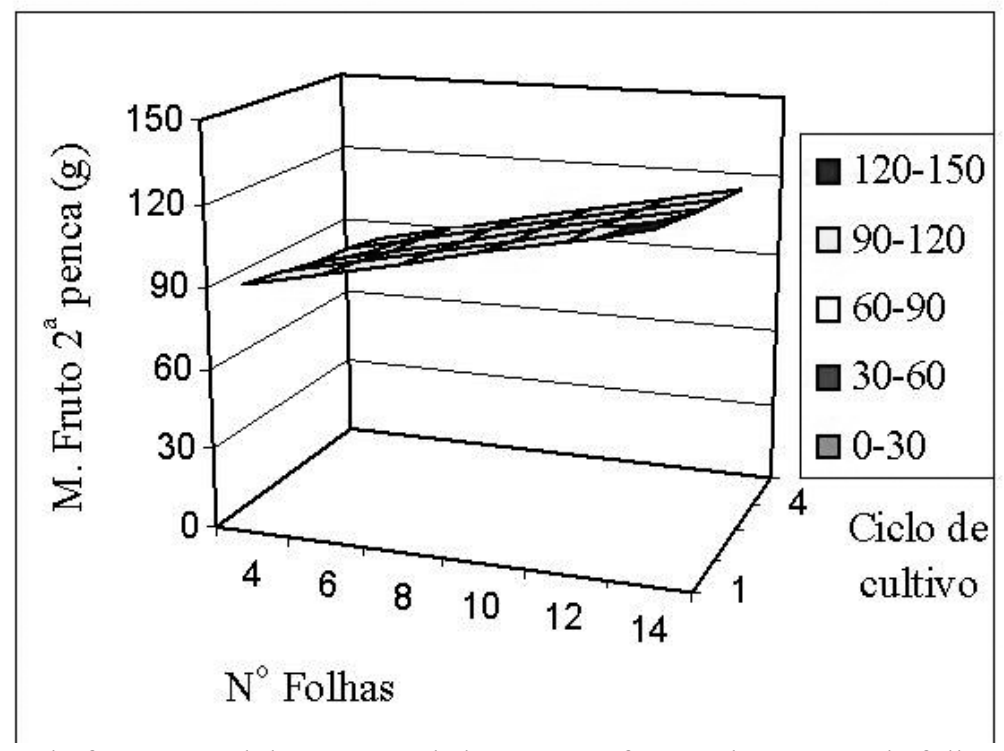

FIGURA 4-Massa do fruto central da $2^{\mathrm{a}}$ penca de banana em função do número de folhas iniciais e do ciclo de cultivo.

\section{CONCLUSÃO}

Para bananeira Prata-Anã cultivada no norte de Minas, o maior número de pencas e de frutos ocorreu com a manutenção de, pelo menos, 10 folhas na planta, porém o adequado enchimento dos frutos, que resulta em massa do cacho, exigiu um mínimo de 12 folhas.

\section{REFERÊNCIAS}

ALVES; J. A; DANTAS J. L. L.; SOARES FILHO, W. dos S.; SILVA, S. de O.; OLIVEIRA, M. de A ; SOUZA, L. da S.; CINTRA, F. L. D.; BORGES, A L.; OLIVEIRA, A M. G.; OLIVEIRA, S. L. de; FANCELLI, M.; CORDEIRO, Z. J. M.; SOUZA, J. da S. Banana para exportação: aspectos técnicos da produção. Brasília: FRUPEX-SPI, 1997. 106 p. (Série Publicações Técnicas, 18).

CAYON, G. Efecto de la remoción de hojas em floración sobre la partición de materia seca, carbohidratos y protínas en el racimo del plátano Dominico-Harton (Musa AAB Simonds). Musarama: The International Bibliographic Abstracts Jounal on Banana and Plantain, Montpellier, v.12, n.1, p.15, 1999.

CARVAJAL, S. B.; SALAZAR M.; C. A.; CAYÓN S.; G.; LOZADA Z.; J. E.; CASTILLO, L. E; VA-
LENCIA, M. J. A. Manejo de plantaciones. In: Belalcazar, C.; Toro-Meza, J. C.; Jaramillo-Celis, R.. El Cultivo del Plátano en el Tropico., Colômbia: INIBAP/ICA/CDCT/CIID, 1991. p.149-242. (Manual de Assistência Técnica , 50).

GONZÁLEZ, P. M. Enfermedades del cultivo del banano. San José: Oficina de Publicaciones de la Universidad de Costa Rica, 1987. 97 p.

INFORME AGROPECUÁRIO. Banana: Produção, colheita e pós-colheita. Belo Horizonte: Epamig, v. 3, n. 196, p. 1-108, 1999.

JACOMINE, P. K. T.; CAVALCANTI, A. C.; FORMIGA, R. A.; SILVA, F. B. R.; BURGOS, N.; MEDEIROS, L. A. R.; LOPES, O. P.; MELO FILHO, H. R. L.; PESSOA S. G. P.; LIMA, P. C. Levantamento exploratório: reconhecimento de solos do norte de Minas Gerais - área de atuação da Sudene. Recife: EMBRAPA-SNLCS/ SUDENEDRN, 1979. p. 10-11.

MOURICHON, X. Overview of progress and results since the first international workshop on Mycosphaerella leaf spot diseases of bananas in 1989. In: INTERNATIONAL WORKSHOP ON MYCOSPHAERELLA LEAF DISEASES, 2., 2002. San José. Proceedings... São José: INIBAP, 2002. p.11-18. 
PEREIRA, L. V.; CORDEIRO, Z. J. M.; FIQUEIRA, A. dos R., HINZ, R. H. MATOS, A. P. Doenças da bananeira. Informe Agropecuário, Belo Horizonte, v.20, n.196, p. 37-47, 1999.

ROBINSON,J.C.; ANDERSON,T. Desarrollo del racimo de banano en relación con el deshoje durante la floración. Musarama- Boletín Bibliográfico Internacional sobre Bananos y Plátanos, Panamá, v.6, n.2, p.4, 1993.
ROBINSON, J. C. Bananas and plantains. Nelspruit, South Africa: Britich Library, 1996. 238p.

SOTO BALLESTERO, M. Bananos: cultivo y comercialización. $2^{\text {nd }}$ ed. San José: Imprenta Lil, 2000. 1 CD- ROM. 